\title{
Life-History Variation in Contrasting Habitats: Flowering Decisions in a Clonal Perennial Herb (Veratrum album)
}

\author{
Elze Hesse, ${ }^{1, *}$ Mark Rees, ${ }^{2, \dagger}$ and Heinz Müller-Schärer ${ }^{1, *}$
}

1. Unit of Ecology and Evolution, Department of Biology, University of Fribourg, Chemin du Musée 10, CH-1700 Fribourg, Switzerland;

2. Department of Animal and Plant Sciences, University of Sheffield, Western Bank, Sheffield S10 2TN, United Kingdom

Submitted January 11, 2008; Accepted May 22, 2008;

Electronically published September 24, 2008

Aвstract: Quantifying intraspecific demographic variation provides a powerful tool for exploring the diversity and evolution of life histories. We investigate how habitat-specific demographic variation and the production of multiple offspring types affect the population dynamics and evolution of delayed reproduction in a clonal perennial herb with monocarpic ramets (white hellebore). In this species, flowering ramets produce both seeds and asexual offspring. Data on ramet demography are used to parameterize integral projection models, which allow the effects of habitat-specific demographic variation and reproductive mode on population dynamics to be quantified. We then use the evolutionarily stable strategy (ESS) approach to predict the flowering strategy-the relationship between flowering probability and size. This approach is extended to allow offspring types to have different demographies and density-dependent responses. Our results demonstrate that the evolutionarily stable flowering strategies differ substantially among habitats and are in excellent agreement with the observed strategies. Reproductive mode, however, has little effect on the ESSs. Using analytical approximations, we show that flowering decisions are predominantly determined by the asymptotic size of individuals rather than variation in survival or size-fecundity relationships. We conclude that habitat is an important aspect of the selective environment and a significant factor in predicting the ESSs.

Keywords: demographic variation, evolutionarily stable strategy (ESS), integral projection models, monocarpic ramets, population dynamics, reproductive mode.

* Corresponding author. Present address: Department of Plant Sciences, University of Oxford, South Parks Road, Oxford OX1 3RB, United Kingdom; email: elze.hesse@plants.ox.ac.uk.

† E-mail: m.rees@sheffield.ac.uk.

` E-mail: heinz.mueller@unifr.ch.

Am. Nat. 2008. Vol. 172, pp. E196-E213. (c) 2008 by The University of Chicago. 0003-0147/2008/17205-50182\$15.00. All rights reserved. DOI: $10.1086 / 591683$
Understanding how different patterns of demographic variation drive the establishment and evolution of life histories is one of the main goals of evolutionary ecology (Fox et al. 2001). Most animal and plant species can be found in a wide range of ecologically distinct habitats, and as a result, individuals of the same species may experience substantial variation in demographic rates, such as survival, growth, and fecundity. These demographic heterogeneities between individuals or groups of individuals can have considerable population dynamical consequences and can generate evolutionary change (e.g., Rees et al. 2000; Saether et al. 2002; Oli and Dobson 2003; Pfister and Stevens 2003; Rose et al. 2005; Benton et al. 2006; Burd et al. 2006; Coulson et al. 2006; Metcalf and Pavard 2007; Sletvold and Grindeland 2007).

The role of demography as a driving force in life-history evolution is widely recognized, yet relatively few studies have quantified how demographic rates, and consequently life-history traits, vary among individuals and populations of the same species (but see, e.g., Bronikowski et al. 2002; Dorken and Barrett 2003; Frederiksen et al. 2005; Lesica and Young 2005). Instead, much of our knowledge about the diversity and evolution of life histories comes from comparative analyses at the interspecific level. This is surprising, given that intraspecific variation allows the study of ecological constraints on life histories without the confounding effect of phylogeny (Frederiksen et al. 2005). Moreover, across-species comparisons, which are often based on only a limited number of populations per species, may become problematic when variation within species is substantial.

Life histories evolve in response to the demographic impact of different environments, being constrained by genetic variance and evolutionary history (Partridge and Harvey 1988). Selection operating on a given life-history trait is likely to be complex, particularly in natural populations, and depends on multiple interactive factors (e.g., Childs et al. 2003; Rees et al. 2004). For example, recent demographic research has demonstrated that variation in 
growth across individuals and years affects selection on the timing of reproduction in monocarpic plants (Rees et al. 2000; Rees and Rose 2002). High mortality, attributable to external factors such as predation and disturbance, selects for earlier maturation in a wide range of species varying from guppies (Reznick et al. 1990, 2002, 2004; Bronikowski et al. 2002) to perennial plants (Reinartz 1984; Wesselingh et al. 1997; Hautekeete et al. 2002). Seed-feeding insect herbivores drive selection on optimal flowering sizes in monocarpic plants, depending on features of the herbivore's ecology such as the size dependence of attack and/or degree of herbivore clustering (Rose et al. 2005). Understanding life-history evolution therefore requires knowledge of the contributions of individual heterogeneities, environmental variance, and density dependence to fitness (Benton et al. 2006).

Monocarpic plants, which reproduce once and then die, are ideal systems for testing demographic and evolutionary ideas because the cost of reproduction is easily quantified and the timing of flowering is a key determinant of fitness (Metcalf et al. 2003). In monocarpic plants, flowering can be delayed for years or even decades, and to explain the adaptive significance of such reproductive delays, evolutionary biologists have traditionally focused on the relative costs and benefits (Cole 1954). In a constant environment, the main benefit of delayed flowering is increased seed production as a result of growth, but this comes at a cost because the longer an individual waits to flower, the greater the chance of dying before reproducing (Klinkhamer et al. 1987; Rose et al. 2005). While we are now beginning to understand the evolutionary dynamics of monocarpic perennial species, relatively little is known about how selection varies among habitats. Although several studies have found an association between habitats with high adult survival and delayed flowering, few quantitative tests of demographic life-history theory exist (e.g., Reinartz 1984; Young 1990; Wesselingh et al. 1997; Lesica and Young 2005).

The majority of monocarpic perennials have relatively simple life histories where reproduction is fatal and seeds are the only type of offspring produced. In many species, however, although flowering is fatal for the ramet, it is also associated with the production of asexual offspring (e.g., Senecio jacobaea, Arabis fecunda, Agave deserti, Digitalis purpurea). In this situation, it is important to distinguish between the genetic and demographic consequences of the different forms of reproduction (Caswell 1985). Sexually produced offspring differ genetically from their parents, whereas asexually produced ones do not, barring somatic mutations, and this has profound consequences for the evolution of breeding systems (MaynardSmith 1978; Cheptou and Schoen 2007). In what follows, we will ignore genetic complications arising from the pro- duction of genetically variable offspring through sexual reproduction, although we will consider possible differences in genetic contribution that arise through the production of seeds and clonal ramets. In addition to these genetic differences, sexually and asexually produced offspring also differ demographically; that is, seedlings have very different survival probabilities compared with clonal ramets (Grace and Wetzel 1982; Cook 1985; Eriksson 1993; Shumway 1995; Gardner and Mangel 1999; Pan and Price 2002; Weppler et al. 2006).

In species producing both asexual offspring and seeds, the timing and size dependency of flowering will be influenced by both forms of reproduction. When considering the evolution of life-history traits, it will therefore be important to take the different demographic consequences of seed and ramet production into account. Integral projection models are particularly suited to the study of the dynamics and evolution of organisms with complex life cycles. First, these models allow individuals to vary continuously in size and allow growth to vary between similar-sized individuals (Easterling et al. 2000; Metcalf et al. 2003). Second, because regression models are used to parameterize the models, it is straightforward to include both size and habitat in each analysis and then use standard statistical approaches to simplify the models. Third, any dependence of offspring size on parental size can be included in the model, so we can correctly account for life-history decisions that influence both the number and quality of offspring produced. Finally, the basic integral projection model can be extended to include discrete stages (Ellner and Rees 2006), such as an age-structured seed bank or a seedling stage, and different modes of reproduction (i.e., sexual and asexual reproduction), and so the effects of particular life-history decisions can be evaluated in the context of the entire life cycle.

In this article, we investigate how demographic variation across habitats and the mode of reproduction affect the flowering strategy, one of the key determinants of the dynamics of plant populations. To address these questions, we quantify demographic variation in Veratrum album L. (Liliales, Melanthiaceae), a clonal perennial herb with monocarpic ramets. Veratrum is characteristic of humid acid soils and can be found in a wide range of (sub)alpine habitats throughout Eurasia, where it can form dense infestations (Kleijn and Steinger 2002). In this species, flowering ramets produce both seeds and asexual offspring. Seeds have limited dormancy and are able to form a shortterm persistent seed bank depending on the habitat (Hesse et al. 2007). Veratrum inflorescences are attacked by a suite of native insect herbivores (Schaffner et al. 2001). These seed feeders may have a major impact on the evolution of reproductive decisions if they alter the fecundity schedule in a size-dependent manner (Rose et al. 2005). 
The article is structured as follows. We first present detailed statistical models of the effects of plant size, habitat, and density on Veratrum, using data on ramet demography collected over three consecutive years in each of five forest, hay meadow, and pasture populations ( $n=15$ populations in total). These demographic data are then used to construct a series of integral projection models (Easterling et al. 2000; Ellner and Rees 2006), which allow the quantification of habitat-specific demographic variation and reproductive mode (i.e., sexual vs. asexual reproduction) on the finite rate of increase $(\lambda)$, net reproductive rate $\left(R_{0}\right)$, and generation time $(T)$. Using the evolutionarily stable strategy (ESS) approach, we then predict the flowering strategy - that is, the relationship between the probability of flowering and plant size-and how this varies between habitats for the different reproductive scenarios. The ESS approach is based on the idea of invasibility and seeks to define a strategy that cannot be invaded by any other strategy under the current constraints on adaptation (Maynard Smith 1982). We determine whether an initially rare strategy can invade, using the finite rate of increase $(\lambda)$. The use of $\lambda$ to measure fitness means that fitness is measured over the entire life cycle, taking all possible demographic transitions into account. This means that fitness is measured in terms of the growth rate of any linear combination of the state variables used to describe the population. So for the Veratrum integral projection model described below, this could be (1) the total number of ramets, (2) the total ramet biomass, (3) the total number of seeds, or any combination of these things. Finally, we use simple analytical approximations to unravel how habitat-specific variation in growth, survival, and reproduction influences the optimal flowering strategy.

\section{Material and Methods}

\section{The Complex Life Cycle of Veratrum}

The life cycle of Veratrum shoots (i.e., ramets) is typical for an alpine monocarpic perennial plant in which reproduction is fatal. Growth starts immediately after snowmelt, and shoots normally die back at the end of summer. Rarely, shoots remain dormant without aboveground structures in one season and reappear the following season. Flowering is infrequent and synchronized among years when up to $\sim 10 \%$ of all shoots within a Veratrum population flower. After flowering, individuals produce both seeds and asexual offspring, which are generated when the apical meristem dies and is replaced by several lateral buds; hence, sexual and asexual reproduction are intimately linked. As the rhizome progressively decomposes from its base, branching will eventually produce a number of separate, genetically identical shoots (Kleijn and Steinger 2002). Seed set is highly variable but can easily exceed 1,000 seeds per inflorescence (Hesse et al. 2007). Seeds possess small winglike structures and are retained in dehiscent pods until they are dispersed by wind in late autumn, winter, or spring. Seeds germinate from April to August bearing only a cotyledon and produce their first real leaf in the following growing season. There is little evidence of a long-term persistent seed bank, but seeds can delay germination for up to 2 years (Hesse et al. 2007). Inflorescences are attacked by a range of insect herbivores (Schaffner et al. 2001); in western Europe, however, the main insect seed feeders are Eupithecia veratraria larvae, which can greatly reduce seed production over the season (U. Schaffner, personal communication). Little is known about the fundamental host range and population biology of E. veratraria (but see Forster and Wohlfahrt 1973).

\section{An Integral Projection Model for Veratrum}

The integral projection model describes how a continuously size-structured population changes in discrete time (Easterling et al. 2000). In the basic integral projection model, the state of the population is described by a distribution function $n(x, t)$, where $n(x, t) d x$ is the number of individuals with size in the range $[x, x+d x]$ at time $t$, so the distribution of sizes next year can be written as

$$
n(y, t+1)=\int_{\Omega} K(y, x) n(x, t) d x,
$$

where $\Omega$ is the range of all possible sizes and $K(y, x)$ is the projection kernel describing all possible transitions from size $x$ to size $y$. While for the majority of the life cycle, shoot diameter is an accurate measure of plant size and can be used to predict fate, there are also several discrete stages in the Veratrum life cycle. To accommodate this complex life cycle, the basic integral model was extended to include an age-structured seed bank ( $i=1$ or 2 years), $S_{i}$, and a discrete seedling/cotyledon stage $C$. Specifically, the number of 1 -year-old seeds in year $t+1$ is given by

$$
S_{1}(t+1)=\left(1-g_{0}\right) s_{0} \int_{\Omega} p_{\mathrm{f}}(x) f_{\mathrm{s}}(x) p_{\mathrm{s}}(x) n(x, t) d x
$$

where $g_{0}$ and $s_{0}$ are the probabilities of germination and survival of freshly produced seeds and $\int_{\Omega} p_{\mathrm{f}}(x) f_{\mathrm{s}}(x) p_{\mathrm{s}}(x) n(x, t) d x$ is the total seed production in year $t$, which is the product of three functions: the probabilities of survival, $p_{\mathrm{s}}(x)$, and flowering, $p_{\mathrm{f}}(x)$, and the expected 
number of seeds produced, $f_{s}(x)$, by an individual of size $x$. The number of 2 -year-old seeds in year $t+1$ is

$$
S_{2}(t+1)=\left(1-g_{1}\right) s_{1} S_{1}(t)
$$

where $g_{1}$ and $s_{1}$ are the probabilities of germination and survival of 1-year-old seeds. The number of plants at the cotyledon stage (seedlings) in year $t+1$ is given by

$$
\begin{gathered}
C(t+1)= \\
p_{\text {est }}\left[g_{0} \int_{\Omega} p_{\mathrm{f}}(x) f_{\mathrm{s}}(x) p_{\mathrm{s}}(x) n(x, t) d x+g_{1} S_{1}(t)+g_{2} S_{2}(t)\right],
\end{gathered}
$$

where $p_{\text {est }}$ is equal to the probability of seedling establishment and the term in brackets is the number of seedlings emerging from freshly produced, 1- and 2-year-old seeds, respectively. Finally, the distribution of established plant sizes is given by

$$
\begin{aligned}
n(y, t+1)= & C(t) p_{\mathrm{sc}} f_{\mathrm{sd}}(y)+\int_{\Omega} p(y, x) n(x, t) d x \\
& +\int_{\Omega} p_{\mathrm{s}}(x) p_{\mathrm{f}}(x) f_{\mathrm{v}}(x) f_{\mathrm{vd}}(y) n(x, t) d x,
\end{aligned}
$$

which is made up of three parts: plants that establish from the seedling stage (first term), established plants that survive and grow (second term), and the production of asexual offspring (third term); $p_{s c}$ is the probability a plant at the seedling stage becomes an established plant, and $f_{\mathrm{sd}}(y)$ is the distribution of recruit sizes. The survivalgrowth function for size $x$ individuals is given by

$$
p(y, x)=p_{\mathrm{s}}(x)\left(1-p_{\mathrm{f}}(x)\right) g(y, x),
$$

where $g(y, x)$ is the probability of an individual of size $x$ growing to size $y ; g(y, x)$ follows a Gaussian probability density function with mean $\hat{\mu}_{g}=a_{g}+b_{g} x$ and variance $\sigma_{g}^{2}(x)=\alpha_{g} \exp \left(-2 \beta_{g} \hat{\mu}_{g}(x)\right)$. This scatter represents both measurement error and real biological variation and, on the basis of the data, decreases with mean shoot size (see "Results"). The probability of flowering, $p_{\mathrm{f}}(x)$, enters the survival-growth function, because flowering is fatal for Veratrum shoots. Production of asexual offspring can be written as

$$
p_{\mathrm{s}}(x) p_{\mathrm{f}}(x) f_{\mathrm{v}}(x) f_{\mathrm{vd}}(y)
$$

where $\log \left(f_{\mathrm{v}}\right)=a_{\mathrm{v}}+b_{\mathrm{v}} x$ gives the number of asexual offspring produced by an individual of size $x$ whose sizes, $f_{\mathrm{vd}}(y)$, follow a Gaussian probability density function with mean $\hat{\mu}_{\mathrm{vd}}=a_{\mathrm{vd}}+b_{\mathrm{vd}} x$ and variance $\sigma_{\mathrm{vd}}^{2}$. Equations (2)(5) define an integral projection model that was parameterized for Veratrum album using the statistical models and distribution functions described in the results (table $1)$.

For numerical solution of the integrals that define the model, we used the midpoint rule for which it is convenient to express the model as a large matrix (Easterling et al. 2000; Childs et al. 2003; Ellner and Rees 2006). In the case of Veratrum, the matrix contains discrete and continuous-state variables and nonzero entries whenever an individual contributes to next year's population (appendix). Under assumptions similar to those required by a matrix model, the integral projection model predicts a finite rate of increase $\lambda$ and net reproductive rate $R_{0}$ (Ellner and Rees 2006). On the basis of these estimates only, we then calculated the generation time as $T=\ln \left(R_{0}\right) / \ln (\lambda)$. The expression $R_{0}$ is the mean number of offspring by which a newborn will be replaced by the end of its life and thus the rate at which the population increases from one generation to the next (Caswell 2001). In the case of Veratrum, $R_{0}$ includes offspring originating from both seeds and asexual reproduction; see Cochran and Ellner (1992), Caswell (2001), and Ellner and Rees (2006, their app. B) for details of the calculation. To quantify how different habitats and the mode of reproduction (sexual vs. asexual reproduction) influence population growth rates and the timing of reproduction in Veratrum, we developed three different integral projection models. These were (1) a base model for each habitat; (2) an asexual reproduction model, with the base model excluding sexual reproduction; and (3) a sexual reproduction model, with the base model excluding asexual reproduction.

\section{Study Sites}

We conducted a field study in 15 Veratrum populations located in five different valleys in the Swiss Pre-Alps (see Hesse et al. 2007); all valleys were located within a 3-40$\mathrm{km}$ distance range. Within each valley, the fate of individuals was followed in three populations situated in ecologically distinct habitats, which were separated $<2 \mathrm{~km}$ from one another: Picea abies dominated forests, hay meadows, and extensively grazed pastures $(n=5$ study populations per habitat). The habitats represent the major vegetation and management types of the species' distribution range. Throughout the Pre-Alps, the species' compositions of pastures and hay meadows are very similar since $90 \%$ of the species occur in both habitats (Schlapfer et al. 1998). In pastures, Veratrum is frequently a locally dominant species that is generally avoided by large her- 
Table 1: Statistical models describing the ramet demography of Veratrum

\begin{tabular}{|c|c|c|c|}
\hline Process, equation, and $\mathrm{P}$ & Forest & Meadow & Pasture \\
\hline \multicolumn{4}{|c|}{$\begin{array}{l}\text { Survival }(n=3,460) \\
\quad \operatorname{logit}\left(p_{\mathrm{s}}\right)=a_{\mathrm{s}}+b_{\mathrm{s}} x-c_{\mathrm{s}} x^{2}\end{array}$} \\
\hline$a_{\mathrm{s}}$ & $-5.61(.99)^{\star * \star}$ & $-.49(.53)$ & $-4.53(1.10)^{\star * *}$ \\
\hline$b_{\mathrm{s}}$ & $7.05(.93)^{\star * *}$ & $4.52(.72)^{\star \star \star}$ & $6.01(1.01)^{\star * *}$ \\
\hline$c_{\mathrm{s}}$ & $1.04(.24)^{\star \star \star}$ & $1.04(.24)^{\star \star \star}$ & $1.04(.24)^{\star \star \star}$ \\
\hline \multicolumn{4}{|l|}{$\begin{array}{l}\text { Growth }(n=3,366) \\
\qquad \hat{\mu}_{g}=a_{g}+b_{g} x\end{array}$} \\
\hline$a_{g}$ & $.14(.03)^{\star * \star}$ & $.11(.02)^{* * *}$ & $.28(.03)^{\star * \star}$ \\
\hline$\sigma_{g}^{2} \stackrel{\stackrel{b}{=}}{=} 0.41 \exp \left(-2 \beta_{g} \hat{\mu}_{g}(\right.$ & $.96(.01)^{\star * *}$ & $.97(.01)^{* * *}$ & $.92(.01)^{\star * *}$ \\
\hline \multicolumn{4}{|l|}{$\begin{array}{l}\text { Flowering }(n=5,759) \text { : } \\
\quad \operatorname{logit}\left(p_{\mathrm{f}}\right)=\beta_{0}+\beta_{\mathrm{s}} x\end{array}$} \\
\hline$\beta_{0}$ & $-115.70(47.21)^{*}$ & $-20.56(1.76)^{\star * *}$ & $-7.08(.59)^{\star * \star}$ \\
\hline$\beta_{\mathrm{s}}$ & $36.53(15.07)^{\star}$ & $6.63(.64)^{\star * \star}$ & $1.50(.21)^{\star \star \star}$ \\
\hline \multicolumn{4}{|c|}{$\begin{array}{l}\text { Vegetative offspring production }(n=45) \text { : } \\
\qquad \log \left(f_{\mathrm{v}}\right)=a_{\mathrm{v}}+b_{\mathrm{v}} x\end{array}$} \\
\hline$a_{\mathrm{v}}$ & $-3.20(1.22)^{\star}$ & $-3.20(1.22)^{\star}$ & $-3.20(1.22)^{\star}$ \\
\hline$b_{\mathrm{v}}$ & $1.24(.39)^{\star *}$ & $1.24(.39)^{* *}$ & $1.24(.39)^{\star *}$ \\
\hline \multicolumn{4}{|c|}{$\begin{array}{l}\text { Size distribution vegetative offspring }(n=82) \text { : } \\
\hat{\mu}_{\mathrm{vd}}=a_{\mathrm{vd}}+b_{\mathrm{vd}} x \text { : }\end{array}$} \\
\hline$a_{\mathrm{vd}}$ & $1.16(.31)^{* * *}$ & $1.16(.31)^{\star \star \star}$ & $1.16(.31)^{\star \star \star}$ \\
\hline$b_{\mathrm{vd}}$ & $.48(.1)^{\star * *}$ & $.48(.1)^{\star * *}$ & $.48(.1)^{\star * *}$ \\
\hline$\sigma_{\mathrm{vd}}^{2}$ & .18 & .18 & .18 \\
\hline \multicolumn{4}{|c|}{ Probability of seed germination: } \\
\hline$g_{0}$ & .26 & .19 & .19 \\
\hline$g_{1}$ & .97 & .55 & .98 \\
\hline$g_{2}$ & .00 & .00 & .00 \\
\hline \multicolumn{4}{|c|}{ Probability of seed survival: } \\
\hline$s_{0}$ & .94 & .75 & .91 \\
\hline$s_{1}$ & .97 & .55 & .98 \\
\hline \multicolumn{4}{|l|}{ Seed-cotyledon: ${ }^{\mathrm{a}}$} \\
\hline $\begin{array}{l}p_{\text {est }} \\
\text { Cotyledon-juvenile: }\end{array}$ & .35 & .99 & .31 \\
\hline$p_{\mathrm{sc}}$ & .52 & .94 & .52 \\
\hline
\end{tabular}

Note: Models are functions of size $x$ and habitat; estimates for demographic parameters (P) are given for each habitat. Values in parentheses are standard errors of parameter estimates.

a Estimated for each habitat by dividing the mean number of seedlings observed by the mean number of seeds that germinated, calculated using the estimated germination probability.

${ }^{\text {b }}$ U. A. Treier and H. Müller-Schärer, unpublished data. Cotyledon survival was not measured experimentally in forest populations and was assumed to be similar to that in pastures.

${ }^{*} P<.05$.

** $P<.01$.

*** $P<.001$.

bivores as a result of its toxicity (Kleijn and Steinger 2002). Pastures are grazed from the beginning of June until the end of August, coinciding with the growing season of Veratrum. Hay meadows are mowed yearly before the majority of Veratrum individuals are able to set seed; individuals at the edge of these populations, however, are often not mowed and so set seed (E. Hesse, personal observation). Forests and pastures generally occur on slightly steeper slopes and higher altitudes compared with hay meadows; the altitudes of the study populations range from 1,020 to 1,555 $\mathrm{m}$ above sea level (Hesse et al. 2007). Populations found in forests are generally smaller than those found in grasslands but contain at least 200 shoots. The size of large populations is impossible to estimate since they spread over many hectares of mountain slopes. Densities in grassland populations are high and can easily reach up to 35 shoots $/ \mathrm{m}^{2}$ in densely infested areas (average shoot density $/ \mathrm{m}^{2} \pm$ SE in the study populations is $0.52 \pm 0.04$, 
$2.43 \pm 0.511$, and $3.35 \pm 0.17$ in forest, hay meadow, and pasture populations $[n=5]$, respectively).

\section{Data Collection}

In late spring 2003, we laid out a core area of $20 \mathrm{~m} \times 50$ $\mathrm{m}$ in each of the 15 study populations, within which we established $601-\mathrm{m}^{2}$ permanent sampling plots. Within these plots, life table parameters and coordinates were measured on individually numbered shoots, which were followed over 3 years (2003-2005). Because shoot density in forest populations was low, we continued sampling until at least 100 shoots were randomly sampled within the core area of each study population. In this way, we marked 542, 675, and 832 ramets across all forest, hay meadow, and pasture populations $(n=5)$, respectively, and followed their fate over 3 years. In addition, we destructively sampled all flowering shoots occurring outside the permanent demographic plots to estimate seed production and predispersal seed predation. Throughout the study, new recruits appearing in the permanent sampling plots received a unique identity, and their coordinates were recorded. The demographic data collected within each sampling plot included the number, identity, and size of shoots and their state (alive/dead, reproductive/ nonreproductive). We used maximum stem diameter at the soil surface as a measure of shoot size because it correlated well with aboveground biomass $\left(r_{\mathrm{p}}=0.92, P<.0001\right.$, $n=54)$ and was robust against trampling by cattle.

For flowering shoots, we also recorded the number of pods and seeds produced. Each pod was dissected to provide counts of seed production and quantitative information on insect damage. Total seed production is given by adding the number of seeds attacked by insects (i.e., seeds having holes as evidence of insect feeding) to the number of seeds not attacked. In this way, we could quantify the percentage of predispersal seed predation for each individual plant by summing over all pods. In addition, we recorded the number and size of asexual offspring produced after flowering in the previous year.

To determine the habitat-specific relationship between seed density and seedling establishment, we established a seed addition experiment in each of the 15 study populations (Turnbull et al. 2000; Munzbergova and Herben 2005). Because seed addition experiments are often extremely sensitive to temporal and spatial variation (Eriksson and Ehrlen 1992), we followed seed germination over 2 years. In late autumn 2003, at the time of natural seed dispersal, Veratrum seeds were added to randomly assigned replicated plots $(n=4)$ using a range of different sowing densities: $0,10,50,100$, or 250 seeds per $100 \mathrm{~cm}^{2}$. Throughout the following two growing seasons (MayAugust 2004-2005), we censused the number of newly emerged seedlings. To distinguish between established and newly emerged seedlings, we removed all newly emerged seedlings from the plots at each census. The effects of habitat and seed sowing density on the fraction of seedlings establishing was analyzed using a full factorial ANCOVA. The minimal adequate model was arrived at by deletion of explanatory variables one at the time from the full model.

\section{Results}

The statistical analyses used to parameterize the integral projection models for Veratrum ramets are based on the pooled data set; that is, data on the fate of individuals obtained in the five replicate study populations were pooled for each habitat, and habitat effects were fitted when significant. We initially used random effects models, which allow the regression coefficients to vary among individuals (Rees et al. 1999). This variability reflects natural heterogeneity due to unmeasured factors, such as individual quality (Pfister and Stevens 2003). However, random individual-specific effects were omitted from the models, because the variance of these effects was negligible. In all analyses, shoot diameter was transformed using natural logarithms. Data analysis and all modeling were performed using R (ver. 2.2.1; http://www.r-project.org) and are summarized in table 1 . Additional details and model selection are discussed below.

\section{Demographic Rates}

Survival probability was modeled using a quasi-binomial logistic regression (Venables and Ripley 2002). The main effects of size $x$, habitat, and the interaction between size and habitat were all highly significant $(P<.0001)$; parameter estimates are given in table 1 . Survival probability initially increased with size, and the addition of a negative quadratic term significantly improved the model fit $(P<$ $.0001)$. The fitted model was of the form $\operatorname{logit}\left(p_{\mathrm{s}}\right)=$ $a_{\mathrm{s}}+b_{\mathrm{s}} x+c_{\mathrm{s}} x^{2}$, where $a_{\mathrm{s}}$ and $b_{\mathrm{s}}$ represent the habitatspecific survival intercept and slope, respectively, and $c_{\mathrm{s}}$ is a negative quadratic term (fig. $1 A-1 C$ ).

Plant size the next year (log scale) was strongly dependent on current size (log scale) and habitat (size $\times$ habitat interaction $P<.0013$ ) and could be described by a linear model with variance decreasing with increasing plant size $(P<.0001$; fig. $1 D-1 F)$. The trend in residual variance was modeled as $\sigma_{g}^{2}=\alpha_{g} \exp \left(-2 \beta_{g} \hat{\mu}_{g}(x)\right)$, where $\hat{\mu}_{g}$ is the fitted value, $\beta_{g}$ is the habitat-dependent variance exponent, and $\alpha_{g}$ is the residual variance (table 1 ). The model was fitted using generalized linear squares (Pinheiro and Bates 2000).

Flowering probability was analyzed using a quasi-binomial logistic regression. The probability of flowering increased with plant size $(P<.0001)$, and there was a sig- 

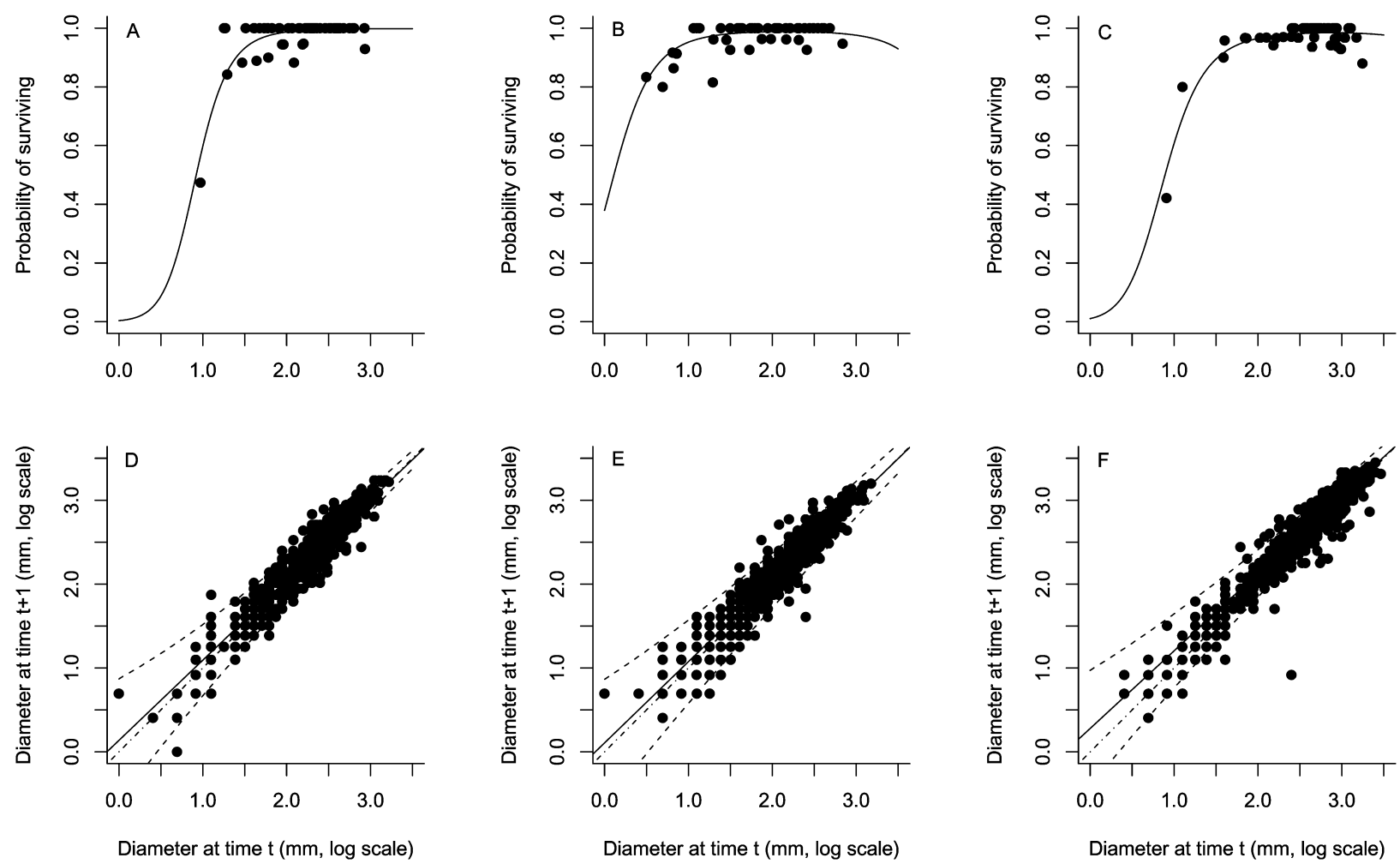

Figure 1: Demographic functions for Veratrum. Survival probability as a function of plant size (natural log transformed) in forest $(A)$, hay meadow $(B)$, and pasture $(C)$ populations. Growth relationship for plant size in successive years in forest $(D)$, hay meadow $(E)$, and pasture $(F)$ populations. Dashed lines show the 2.5 and 97.5 percentiles of the fitted variance function. Note that we divided the data into 50 equal-sized categories and calculated the probability and mean size for each category; the analyses, however, were performed on the raw data. Parameter values for the fitted functions are given in table 1 .

nificant size $\times$ habitat interaction term $(P<.0001$; fig. $2 A-2 C)$. In other words, the slope of the flowering probability-size relationship differed significantly across habitats. During the study period, relatively few individuals flowered: we observed a total of 2, 26, and 177 flowering individuals versus $1,493,1,926$, and 2,337 nonflowering individuals in forests, hay meadows, and pastures, respectively. In forest populations, only two flowering individuals were observed, so we explored whether the data for forest and pasture populations could be combined and a single regression used for both habitats. However, the habitatspecific flowering function provided a significantly better fit compared with the combined flowering function $(F=62.12, \mathrm{df}=2,5,755, P<.0001)$, and so habitatspecific regressions were retained; combining forest and meadow populations gave similar results. When we consider the evolution of the flowering function, we refer to the habitat-specific intercept and slope as $\beta_{0}$ and $\beta_{s}$, respectively (table 1).

Asexual offspring production was modeled using a generalized linear model with a Poisson error structure and a log link function $(n=45)$. Offspring production increased with parental size $(P=.003)$ but did not differ significantly among habitats $(P=.38)$; the fitted model was of the form $\log \left(f_{\mathrm{v}}\right)=-3.20(1.22)+1.24(0.39) x$; numbers in parentheses are standard errors. Moreover, offspring size $(n=82)$ was strongly dependent on parental size $x(P<.0001)$ and could be described by a normal distribution with mean $1.16(0.31)+0.48(0.1) x$ and variance 0.18 (fig. $2 D-2 F$ ).

Seed production data were pooled for all habitats $(n=58)$. Seed production was strongly size dependent $(P<.0001)$ and highly variable (fig. $3 A)$ and was modeled using a negative binomial generalized linear model with a logarithmic link function (Venables and Ripley 2002); the fitted model was of the form $f_{s}=\exp (2.01[0.88])+$ $1.68[0.33] x)$. Predispersal seed predation was highly variable among individuals, ranging from $12 \%$ to $98 \%$ (fig. $3 B)$, and was independent of plant size $(P=.375)$; on average, seed production was reduced by $62 \%$ as a result of seed predation.

No seedlings emerged in the control plots of the seed 
addition experiment. In the growing season following seed addition, seedling emergence was extremely low $(<1 \%)$, which is consistent with data on soil seed bank persistence (Hesse et al. 2007). Whereas habitat had a strong effect on seedling emergence $(F=17.69$, df $=2,44, P<.0001)$, seedling emergence did not differ significantly across sowing densities $(F=2.93$, $\mathrm{df}=1,44, P=.09)$. The habitatspecific probabilities of survival from seed to seedling $\left(p_{\text {est }}\right)$ and seedling to juvenile $\left(p_{\text {sc }} ; \mathrm{U}\right.$. A. Treier and $\mathrm{H}$. Müller-Schärer, unpublished data) are given in table 1 . Note that in both cases, $p_{\text {est }}$ and $p_{\text {sc }}$ are estimated from cumulative counts during the year, and in some cases, plants, particularly seedlings, may have died before the established plant population was censused, resulting in both parameters being overestimates. The dynamics of the seed bank are determined by germination and seed survival, which occurred with probabilities $g_{i}$ and $s_{i}$, respectively (table 1). The half-life of seeds in the seed bank was approximately 1.5 years (Hesse et al. 2007).

Data were not available on the size of seedlings derived from plants of different sizes, but evidence from other systems suggests a low maternal effect on seedling size (Weiner et al. 1997; Sletvold 2002). Thus, the distribution of seedling size was assumed to be independent of parental size; seedling size did not differ significantly between habitats $(P=.59)$ and was described by a normal distribution with mean 1.05 and variance 0.72 .

Finally, we assessed the impact of intraspecific competition on the growth and survival probability of established plants by incorporating the number of Veratrum shoots per 1-m sampling plot into the previously described regression analyses (table 1). Both survival and growth decreased with local shoot density; the effects were, however, only marginally significant ( $P=.12$ and .07 , respectively) and were not included in the models.

\section{Population Growth and Generation Time}

The base model predicted grassland populations to expand more rapidly than forest populations (table 2 ). In addition, both $R_{0}$ and $\lambda$ were substantially higher in hay meadow populations compared with pasture populations (table 2). Preventing individuals from sexual reproduction, but not from asexual reproduction, reduced both $\lambda$ and $R_{0}$ to $\approx 1$, indicating that the populations will increase even without seed set (table 2).

The generation time in the forest populations was $\approx 3$ times that in the grassland populations $(\approx 30$ vs. $\approx 10$ years, respectively). We explored how the observed variation in the probability of flowering versus size relationship affected generation time by constructing an integral projection model in which we replaced the flowering strategy of forest populations with that of the pasture populations.
Using this model, the differences in generation time were greatly reduced (generation time in the forest was $T \approx$ 15 years), which suggests that variation in generation time across habitats is mainly driven by differences in the flowering strategies.

\section{ES Flowering Strategies}

In order to identify the evolutionarily stable flowering strategies, we need to first define what we mean by a flowering strategy and then characterize the ESSs. We define the flowering strategy by the fitted relationship between the probability of flowering, $p_{\mathrm{f}}$, and plant size, namely,

$$
p_{\mathrm{f}}=\frac{\exp \left(\beta_{0}+\beta_{\mathrm{s}} x\right)}{1+\exp \left(\beta_{0}+\beta_{\mathrm{s}} x\right)},
$$

where $\beta_{0}$ and $\beta_{\mathrm{s}}$ are the fitted intercept and slope, respectively, and $x$ is the log-transformed shoot diameter; see table 1 for parameter estimates and figure $2 A-2 C$. Note that because we are using a logit link function, the parameters $\beta_{0}$ and $\beta_{\mathrm{s}}$ can take any values, whereas the probability of flowering always lies in the interval $[0,1]$. The fitted relationships between size and the probability of flowering are gradual (fig. $2 A-2 C$ ), representing possibly a constraint or else a decision that depends on plant size at some time between censuses. We imposed a gradual size dependence on the flowering strategy by holding the size slope $\left(\beta_{\mathrm{s}}\right)$ of the flowering function at its estimated value and varying the intercept $\left(\beta_{0}\right)$. Therefore, in each of the habitats, $\beta_{0}$ uniquely characterizes the flowering strategy. Reducing $\beta_{0}$ has the effect of reducing the probability of flowering for all plant sizes, and so the mean size at flowering increases, whereas increasing $\beta_{0}$ has the opposite effect, and the mean size at flowering decreases. Note that equation (8) defines a probabilistic reaction norm; see Heino et al. (2002) for a discussion of the estimation and interpretation of probabilistic reaction norms.

The characterization of the evolutionarily stable flowering strategies in this system is complicated because two types of offspring are produced, namely, sexually produced seeds and asexually produced clonal ramets. There are two issues here. First, there could be different genetic contributions through seeds and ramets. Second, given that seeds and clonal ramets have different reproductive values, how should we define the success of a strategy?

First, we focus on the possible different genetic contributions of different types of offspring. Imagine a diploid, obligately outcrossing, cosexual plant, like Veratrum, and assume that the flowering strategy is controlled by a single locus with two alleles, a common type $a a$ and a rare mutant $A a$; because we are dealing with the invasion dynamics, 

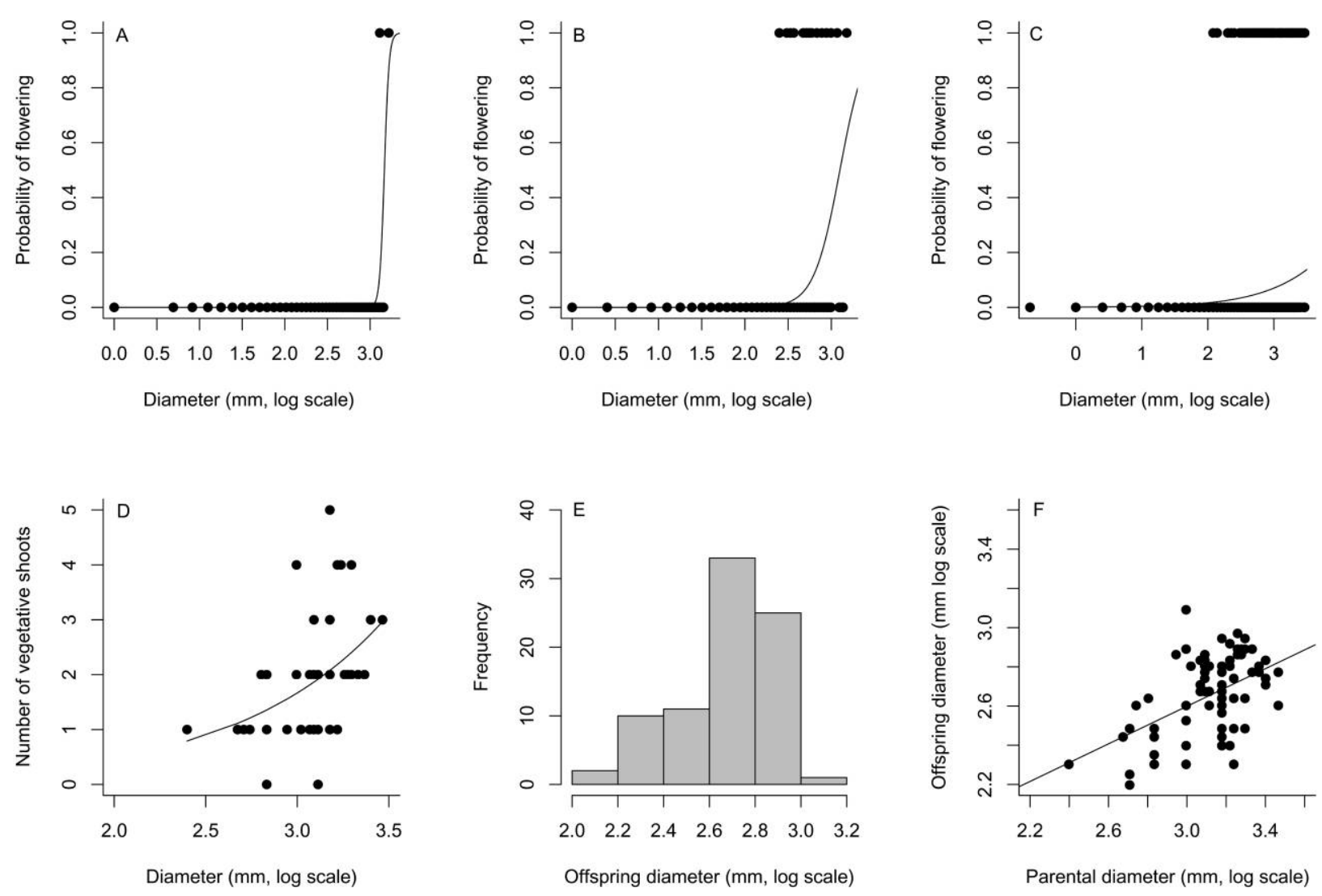

Figure 2: Demographic functions for Veratrum. Flowering probability as a function of plant size (natural log transformed) in forest $(A)$, hay meadow $(B)$, and pasture $(C)$ populations. Vegetative offspring production after flowering in the previous growing season: offspring number as a function of parental shoot size $(D)$, offspring size distribution $(E)$, and mean offspring size as a function of parental shoot size $\left(F\right.$; adjusted $\left.R^{2}=0.22\right)$. Parameter values for the fitted functions are given in table 1.

we can ignore the $A A$ genotype since it will be rare under random mating. We assume that density dependence acts on recruitment of seedlings and clonal ramets, such that seedlings have a probability $p_{\text {est }}$ of establishing, whereas in clonal ramets, the probability is $c p_{\text {est }}$, where $c$ is typically $>1$, reflecting the larger initial investment in the clonal ramets. So at equilibrium,

$$
p_{\text {est }}(a a)\left[c F_{\mathrm{c}}(a a)+F_{\mathrm{s}}(a a)\right]=1
$$

where $F_{\mathrm{c}}$ and $F_{\mathrm{s}}$ are the per capita number of clonal ramets and seeds produced by an established seedling or clonal ramet, allowing differential growth and survival until flowering. The question then is whether we need to weight $F_{\mathrm{s}}(A a)$ differently from $F_{\mathrm{c}}(A a)$ when considering invasion by a rare mutant. All clonal ramets will by definition be $A a$. The total number of $A a$ seeds produced by $A a$ individuals will be $1 / 2 F_{\mathrm{s}}(A a) n(A a)$, where $n(A a)$ is the number of $A a$ plants; since nearly all $A a$ plants will be fertilized by $a a$ plants, half of their offspring will be $A a$. In addition, we need to account for the fertilization of $a$ a plants by pollen from $A a$ plants. Assuming that pollen production is proportional to fecundity, the proportion of pollen coming from $A a$ plants is

$$
\frac{F_{\mathrm{s}}(A a) n(A a)}{F_{\mathrm{s}}(A a) n(A a)+F_{\mathrm{s}}(a a) n(a a)} \approx \frac{F_{\mathrm{s}}(A a) n(A a)}{F_{\mathrm{s}}(a a) n(a a)} .
$$

The number of seeds produced by $a a$ plants is $F_{s}(a a) n(a a)$. Multiplying this by equation (10) shows that there will be $F_{\mathrm{s}}(A a) n(A a)$ seeds fertilized by $A a$ plants, and half of these will be $A a$, so the total number of $A a$ seeds produced via maternal and paternal routes is $F_{\mathrm{s}}(A a) n(A a)$. We therefore conclude that if we know the per capita rates of ramet $\left(F_{c}\right)$ and seed production $\left(F_{\mathrm{s}}\right)$ of $A a$ plants, we can predict whether invasion will succeed; that is, $p_{\text {est }}(a a)\left[c F_{c}(A a)+F_{s}(A a)\right]>1$. Hence, under this set of assumptions, we avoid the complication of having to weight seeds and clonal offspring differently to account for different genetic contributions. 

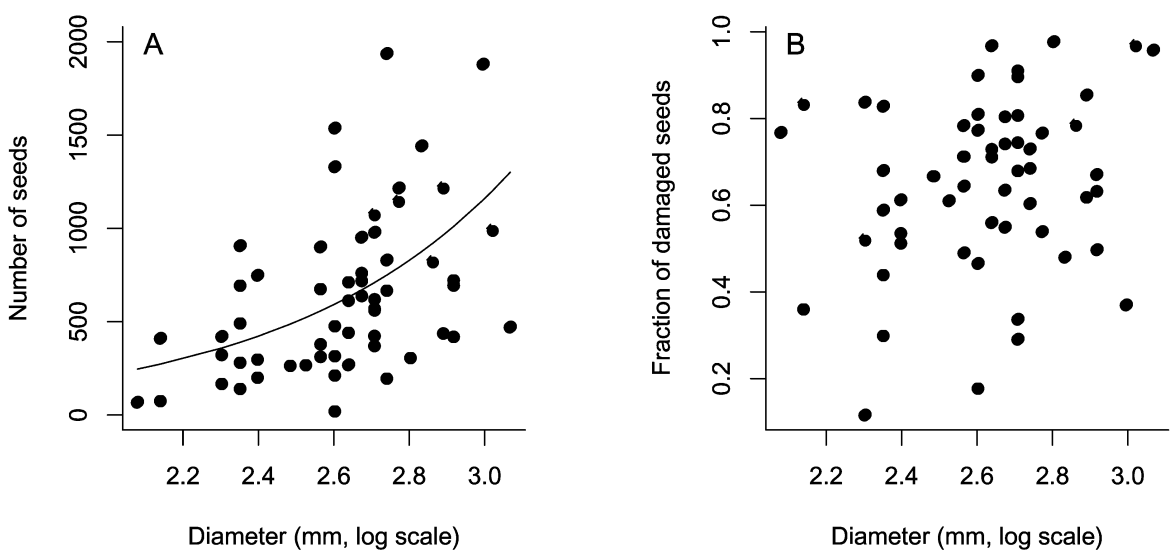

Figure 3: Total seed production $(A)$ and the fraction of damaged seeds $(B)$ as a function of the shoot size of flowering individuals.

We now consider the complications that arise when the different types of offspring produced are not equivalent demographically. The standard ESS analysis for a size- or age-structured population with density dependence acting on the very young (Mylius and Diekmann 1995; Ellner and Rees 2006) assumes a single type of offspring, say, seeds or ramets, and then uses the number of offspring produced over an individual's lifetime, $R_{0}$, to characterize the ESS. When there are multiple offspring types, this approach is inappropriate for two reasons: (1) it assumes that one can characterize the success of a strategy by the total number of all offspring types produced and (2) it assumes that density dependence acts equally on all offspring types. Both these assumptions are appropriate only when all offspring types are equivalent demographically, which is extremely unlikely for Veratrum album seeds and asexually produced ramets, given their vastly differing initial sizes (seed dry weight \pm SE: $3.32 \pm 0.01 \mathrm{mg}$ [Hesse et al. 2007]; clonal ramet dry weight \pm SE: $7.5 \pm 0.92 \mathrm{~g}$ ).

We therefore need an approach that allows offspring types to have different demographies and sensitivities to density dependence. As before, we assume that density dependence acts on recruitment of seedlings and clonal ramets, such that seedlings have a probability $p_{\text {est }}$ of establishing, whereas in clonal ramets, the probability is $c p_{\text {est }}$, where $c$ is typically $>1$. To find the evolutionarily stable flowering strategy for a given value of $c$, we followed the following procedure. (1) We used the Veratrum integral projection model (eqq. [2]-[5], with the probability of a ramet establishment equal to $c p_{\text {est }}$ ) to solve numerically for $p_{\text {est }}$ such that the population was at equilibrium $(\lambda=1)$. This defined the resident environment. (2) Given $p_{\text {est }}$ set by the resident flowering strategy, we then maximized $\lambda$ as a function of $\beta_{0}$ and denoted the value of $\beta_{0}$ that maximized $\lambda$ as $\tilde{\beta}_{0}$. (3) If the value of $\lambda$ corresponding to $\tilde{\beta}_{0}$ was close to 1 within a specified tolerance $(0.00001)$, we stopped; otherwise, we repeated from step 1 but with $\beta_{0}=\beta_{0}$.

If we assume that reproduction occurs only through the production of seeds or clonal ramets, then the standard approach of maximizing $R_{0}$ is appropriate and provides a simple check that the iterative approach described above correctly finds the ESS. For each candidate ESS, we calculated $\lambda$ for a range of alternative flowering strategies; the plot of $\lambda$ against the flowering strategy $\left(\beta_{0}\right)$ then defines a fitness landscape (Childs et al. 2003), the topography of which describes the strength of selection acting on alternative strategies. For comparison, we also calculated $\lambda$ assuming that the populations are not density regulated

Table 2: Effect of differential sexual and vegetative reproduction on population growth and generation time in Veratrum populations

\begin{tabular}{lccc}
\hline Model and habitat & $\lambda$ & $R_{0}$ & $T$ (years) \\
\hline 1: & & & \\
$\quad$ Forest & 1.12 & 30.85 & 29.54 \\
$\quad$ Meadow & 1.49 & 77.18 & 10.92 \\
$\quad$ Pasture & 1.28 & 28.28 & 13.62 \\
2: & & & \\
$\quad$ Forest & 1.02 & 1.88 & 28.26 \\
$\quad$ Meadow & 1.02 & 1.24 & 10.13 \\
$\quad$ Pasture & 1.06 & 1.86 & 10.92 \\
3: & & & \\
$\quad$ Forest & 1.10 & 28.98 & 33.40 \\
$\quad$ Meadow & 1.42 & 75.94 & 12.19 \\
$\quad$ Pasture & 1.24 & 26.40 & 14.97 \\
\hline
\end{tabular}

Note: Finite rate of increase $(\lambda)$, net reproductive rate $\left(R_{0}\right)$, and generation time $(T)$ were calculated using three different integral projection models: (1) a base model for each habitat, (2) an asexual reproduction-only model, and (3) a sexual reproduction-only model. 
and so continue to increase at the current rate (table 2; model [1]).

The fitness landscapes for the density-dependent ESSs show that, irrespective of habitat and type of reproduction, the evolutionarily stable flowering strategy lies within the 95\% confidence interval (CI) for the estimated flowering intercept $\beta_{0}$ (fig. $4 A-4 C$ ). In each case, the ESSs obtained by maximizing $R_{0}$ are in excellent agreement with that obtained by iteratively maximizing $\lambda$. In the forest populations, $\lambda$ plateaus at 0.9978 (fig. $4 A$ ) when $\beta_{0}$ is small $(\ll 0)$. In these populations, no plant ever flowers because the probability of flowering is extremely small; populations thus decline at a rate equal to the survival probability of large plants (0.9978). In all habitats, the ESSs for purely asexual reproduction are slightly larger than those for purely sexual reproduction, corresponding to a larger size at flowering for the purely sexual reproduction ESSs. This is a consequence of the benefits from increased flowering size accruing more rapidly for seed compared with ramet production (the exponents for the relationships between seeds or ramets and plant size being 1.68 and 1.24, respectively).

For the density-independent models (fig. 4D-4F), we see strong selection for flowering at smaller sizes (large $\beta_{0}$ 's, so even small individuals have a high probability of flowering) in all habitats, provided seeds are produced. In each of these scenarios, the optimal flowering strategy is for all established plants to flower in their first year, which maximizes the rate of population growth, $\lambda$. In contrast, when reproduction occurs only through the production of ramets, the populations increase slowly (table 2; model [2]), and so the optimal strategy is similar to the habitatspecific density-dependent ESSs.

To explore how the evolutionarily stable flowering strategies vary in response to the sensitivity of ramets to density dependence $(c)$, we computed the ESSs for $c$ in the range $[0.0001,10,000]$; the resulting ESSs for each habitat are shown in figure 5. In all cases, the ESSs lie within the 95\%

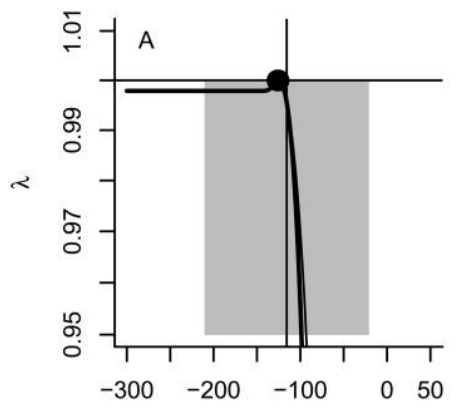

Intercept of flowering function $\beta_{0}$

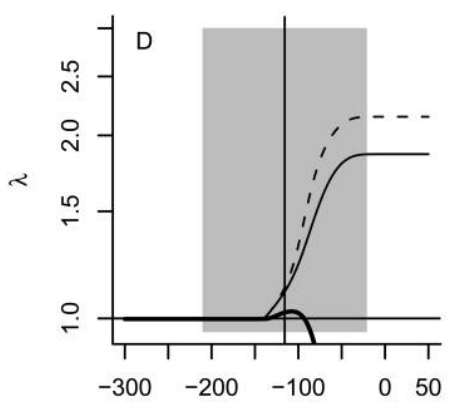

Intercept of flowering function $\beta 0$

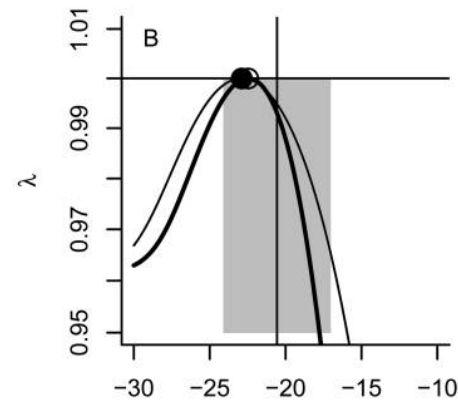

Intercept of flowering function $\beta_{0}$

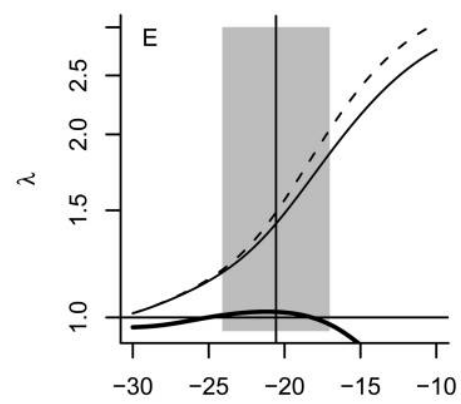

Intercept of flowering function $\beta_{0}$

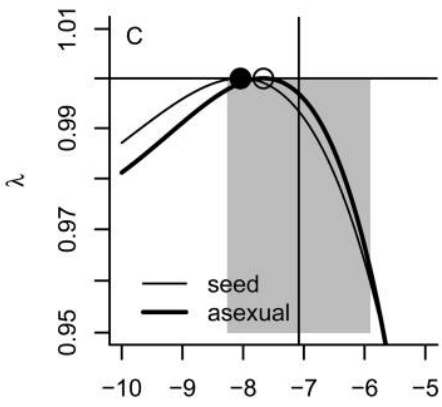

Intercept of flowering function $\beta 0$

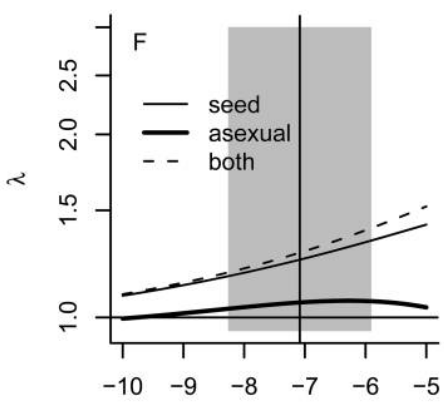

Intercept of flowering function $\beta 0$

Figure 4: Fitness landscapes for the density-dependent evolutionarily stable strategies (ESSs; $A-C)$ and the density-independent $\lambda(D-F)$, as a function of the flowering strategy $\left(\beta_{0}\right)$. Density-dependent ESSs for forest $(A)$, hay meadow $(B)$, and pasture $(C)$ populations for two cases: $(1)$ seeds only ( $c=0$; thin line) and (2) ramets $(c=10,000$; thick line), which were much less affected by density dependence and closely approximated the ramet-only ESS. In each case, the circles at the top of each curve are the ESSs calculated by maximizing $R_{0}$, assuming only sexual (filled circles) or asexual (open circles) reproduction. The shaded area indicates the $95 \%$ confidence intervals around the observed flowering intercept (vertical line). The horizontal line presents the population growth rate in demographic steady state $(\lambda=1)$. Density-independent $\lambda$ 's for forest $(D)$, hay meadow $(E)$, and pasture $(F)$ populations for populations reproducing by (1) only seeds (thin line), (2) only ramets (thick line), and (3) both seeds and ramets (dashed line). 
CIs for the habitat-specific $\beta_{0}$ 's. Plants produce many more seeds than ramets (the ranges for the numbers of seeds and ramets produced are [20-1,937] and [0-5], respectively), and so for low values of $c$, the ESSs are close to those assuming the plants reproduce by seed only. For large values of $c$, however, the ESSs shift toward the rametonly ESSs. In all habitats, there is excellent agreement between the $c \approx 0$ and $c \gg 1$ ESSs obtained by iteratively maximizing $\lambda$ and the ESSs obtained by maximizing $R_{0}$ for the seed-only and ramet-only scenario, respectively.

\section{Approximate ESSs and Demographic Contributions}

To understand how different aspects of Veratrum's demography influence the flowering strategy, we used the 1year look-ahead approach described by Rees et al. (2000). The approach derives a switch value $L_{\mathrm{s}}$, which is the size at which fecundity next year is equal to fecundity this year, allowing for variation in survival and growth. Individuals with $L(t)>L_{\mathrm{s}}$ are predicted to flower, and $L_{\mathrm{s}}$ is given by the solution to the following equation:

$$
L_{\mathrm{s}}=\frac{a_{g}}{1-b_{g}}+\frac{\ln \left(p_{\mathrm{s}}\left(L_{\mathrm{s}}\right)\right)}{B\left(1-b_{g}\right)}+\frac{B \sigma_{g}^{2}\left(L_{\mathrm{s}}\right)}{2\left(1-b_{g}\right)} .
$$

The first term on the right-hand side of the equation represents the asymptotic size, given by the intercept $a_{g}$ and slope $b_{g}$ of the growth equation. The second term is dependent on the probability of survival $\ln \left(p_{s}\left(L_{s}\right)\right)$ : as the probability of survival increases, the payoff from delayed reproduction increases, and so $L_{\mathrm{s}}$ increases. The survival term is offset by $b_{g}$ and the slope of the relationship between seed or ramet production and plant size $B$ : the larger the payoff from waiting, as a result of faster growth or increased fecundity, the larger the $L_{\mathrm{s}}$ (Rees et al. 2000). The third term captures the effect of variation in growth, $\sigma_{g}^{2}$, which selects for larger sizes at flowering (Rees et al. 2000; Rees and Rose 2002).

To unravel how demographic rates influence the flowering strategy, we calculated the switch value using the habitat-specific demographic functions listed in table 1. More specifically, we assumed that plants reproduced through the production of either ramets or seeds, and we quantified how the mode of reproduction affects the switch value by using the appropriate slope $(B)$ of the seed/ramet versus plant size relationship in equation (11). We assumed survival and variation in growth to be size dependent; see table 1 for functions. To compare the approximation with the observed flowering strategy, we calculated the predicted flowering intercept using $\beta_{0}=-\beta_{s} L_{s}$; the results are given in table 3 .

Under both reproductive scenarios, the 1-year lookahead flowering strategies were similar to those observed in the field (table 3): in forest and hay meadow populations, the predicted flowering strategy lies within the 95\% $\mathrm{CI}$ of the observed flowering strategy, and the models only slightly underestimate the flowering size of individuals in pasture populations (table 3). The 1-year look-ahead approach provides an excellent approximation to the ESSs calculated by maximizing $R_{0}$ despite ignoring (1) growth opportunities more than 1 year ahead (Rees et al. 1999, 2000) and (2) ramet size increasing with parental size. Both these effects select for larger sizes at flowering, because they increase the payoff from flowering at larger sizes, and so the 1-year look-ahead underestimates the ESS $\beta_{0}$ in all cases. As a result of limited variation in growth and low
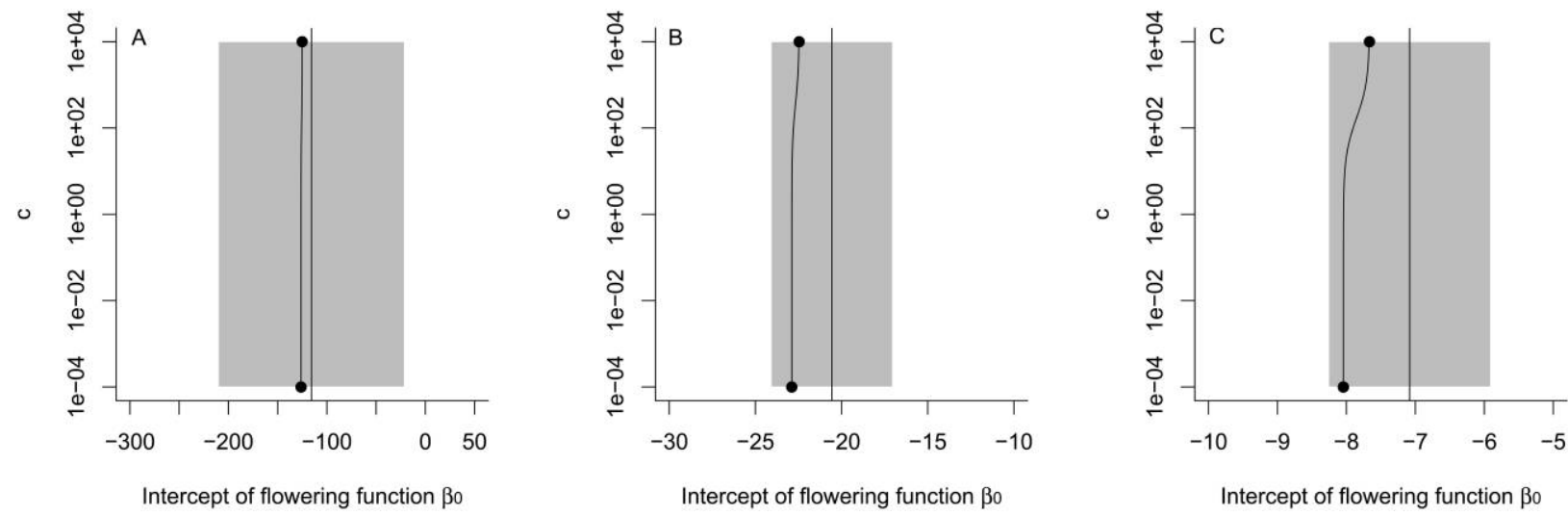

Figure 5: Predicted evolutionarily stable flowering strategies, $\beta_{0}$, as a function of the establishment advantage of asexual offspring $c$ in forest $(A)$, hay meadow $(B)$, and pasture $(C)$ populations. The circles at the ends of each curve correspond to the evolutionarily stable strategies predicted by maximizing $R_{0}$ assuming only sexual $(c \approx 0)$ or asexual $(c \gg 1)$ reproduction. The shaded area indicates the $95 \%$ confidence intervals around the observed flowering intercept (vertical line). 
Table 3: Analytical approximation of the evolutionarily stable (ES) flowering intercept for forest, hay meadow, and pasture populations

\begin{tabular}{lcccc}
\hline Habitat & Sexual reproduction & $\begin{array}{c}\text { Vegetative } \\
\text { reproduction }\end{array}$ & Observed & $\begin{array}{c}\text { 95\% CIs of observed } \\
\text { flowering intercept }\end{array}$ \\
\hline Forest & $-123.19(-126.21)$ & $-120.67(-125.10)$ & -115.70 & $-210.12,-21.28$ \\
Meadow & $-20.63(-22.89)$ & $-19.90(-22.46)$ & -20.57 & $-24.08,-17.04$ \\
Pasture & $-5.48(-8.04)$ & $-5.36(-7.67)$ & -7.08 & $-8.26,-5.91$ \\
\hline
\end{tabular}

Note: The ES flowering intercept $\left(\beta_{0}=-\beta_{s} L_{s}\right)$ was calculated by solving equation (11) using either the slope of the seed production function $(B=1.68)$ or the slope of the vegetative offspring production function $(B=1.24)$. Under both reproductive scenarios, survival and variation in growth were assumed to be both size and habitat dependent. Numbers in parentheses are the evolutionarily stable strategies calculated by maximizing $R_{0}$. CI $=$ confidence interval.

mortality rates, switch values were relatively insensitive to changes in the slope of the fecundity relationship (table 3 ). We illustrate this more clearly by plotting a wide range of fecundity slopes against the predicted ES flowering intercept using the habitat-specific integral projection models (fig. 6). Under both reproductive scenarios, there is very little variation in the ESS $\beta_{0}$ as $B$ varies, and in all cases, the ESSs lie within the $95 \%$ CIs. Rather than variation in $B$ driving the ESSs, the asymptotic size of individuals in the different habitats appears to be critical. For instance, using equation (11), we find the fractional contribution of asymptotic size (first term) to the switch value to be $0.901,0.795$, and 0.900 in forest, hay meadow, and pasture populations, respectively, for the sexual reproduction scenario (calculated as first term $/ \Sigma \mid$ terms $\mid$ ). This strongly suggests that variation in asymptotic size is the key determinant of variation in the flowering strategy.

\section{Discussion}

Results from our field study indicated that demographic rates differed substantially across habitats. Using various modeling approaches, we demonstrated that this demographic variation greatly affected the evolutionarily stable flowering strategy: the ESSs differed between habitats and were in excellent agreement with the observed habitatspecific flowering strategies. In contrast, the reproductive mode had little effect on the evolutionarily stable flowering strategy, a result of the ESS being relatively insensitive to changes in the slope of the size-fecundity relationship. We discuss first the proximate causes of our findings and then how various model assumptions may have affected our predictions of the evolutionarily stable flowering strategy.

\section{Demographic Variation}

Demographic rates varied substantially both between individuals and across habitats. For instance, individual growth was significantly higher in pastures than in forests and hay meadows. This could be explained by the follow- ing: cattle generally avoid Veratrum individuals because of their toxicity, which may give them a competitive advantage over more palatable plant species (Kleijn and MüllerSchärer 2006). In hay meadow populations, individual growth was slow, probably as a result of biomass removal before the end of the growing season. In all habitats, relative growth rates declined with increasing size, a widespread pattern in vascular plants. This is probably a consequence of a reduction in resources and resource conversion efficiency and increasing maintenance or structural costs (Enquist et al. 1999). Survival rates initially increased with size and differed significantly among habitats. Juvenile mortality rates, in particular, were higher in forest and pasture populations than in hay meadow populations, which could be attributable to external factors such as tree fall and trampling by cattle (U. A. Treier and H. Müller-Schärer, unpublished data). As the potential payoff and mortality risks vary with growing conditions, we expect the timing of reproduction to differ among populations, which ultimately affects population growth and a population's response to variation in the environment.

\section{Population Dynamics}

The integral projection models predicted rapid growth of our study populations, with grassland populations growing faster than forest populations. Indeed, in agreement with our findings, Veratrum album populations have greatly increased over the past decade mainly as a result of reduced land use in most parts of Europe (Spiegelberger et al. 2008), including at our study sites in the Pre-Alps in Switzerland (N. Doutaz, Institut agricole de Grangeneuve, Fribourg, Switzerland, personal communication). However, when interpreting the model predictions, it is important to remember that $p_{\text {est }}$ and $p_{\text {sc }}$ were likely to be overestimated, and so the predicted rates of population growth will also be overestimated.

Differences in population growth between habitats largely disappeared when sexual reproduction was set to 0 (table 2). This suggests that differences in population 


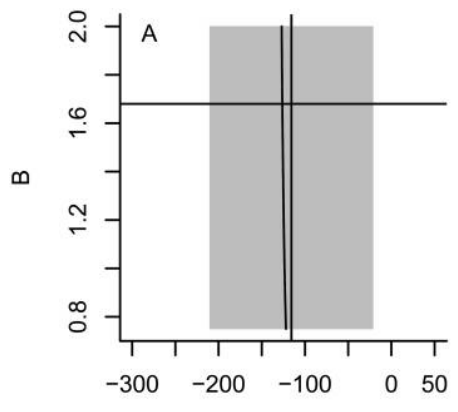

Intercept of flowering function $\beta 0$

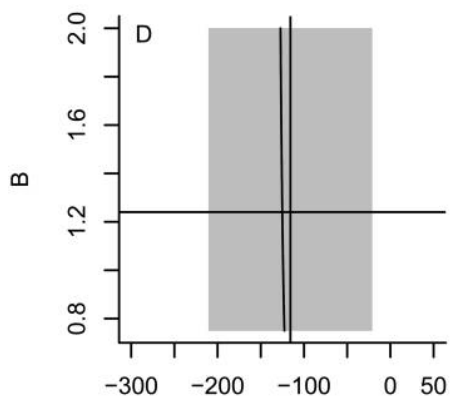

Intercept of flowering function $\beta 0$

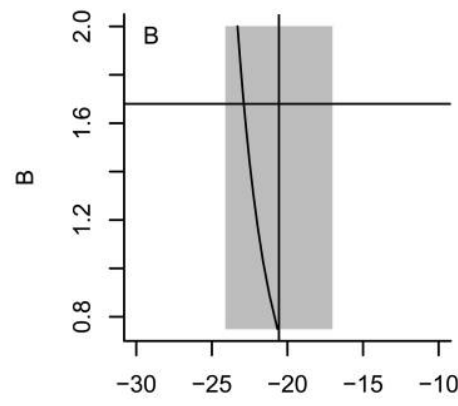

Intercept of flowering function $\beta 0$

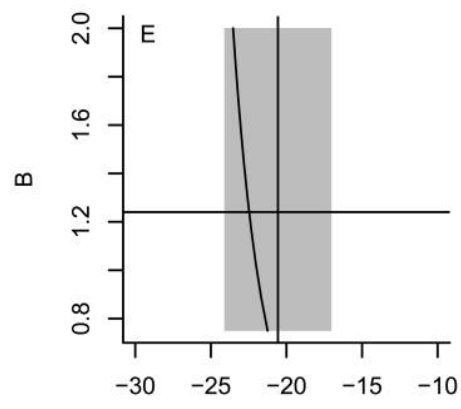

Intercept of flowering function $\beta 0$

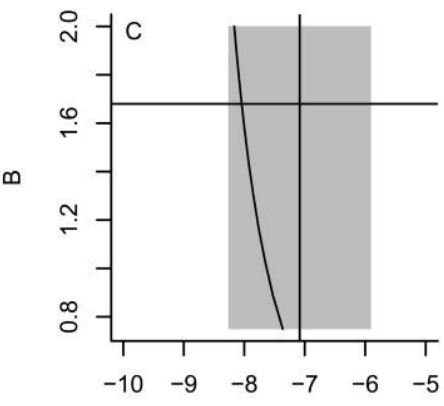

Intercept of flowering function $\beta 0$

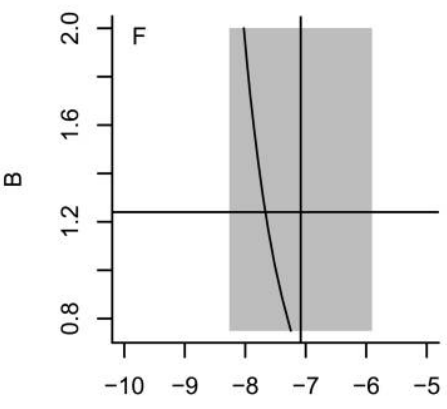

Intercept of flowering function $\beta_{0}$

Figure 6: Predicted evolutionarily stable flowering strategy, $\beta_{0}$, as a function of the slope of the fecundity function, $B$, assuming plants produce only seeds in forest $(A)$, hay meadow $(B)$, and pasture $(C)$ populations or only ramets in forest $(D)$, hay meadow $(E)$, and pasture $(F)$ populations. The shaded area indicates the $95 \%$ confidence intervals around the observed flowering intercept (vertical line). The horizontal line is the estimated value of $B$ for seeds (1.68) and ramets (1.24).

growth were mainly due to variation in reproductive success through seed production and seedling recruitment. Although there is evidence for reduced sexual reproduction and seedling survival in several alpine plant species (Chambers 1995; Forbis 2003), recent work on Geum reptans, a long-lived alpine species, has demonstrated that contributions from sexual reproduction to population growth can be substantial (Weppler et al. 2006). In addition, a population genetic study has revealed substantial genetic variation within and across natural $V$. album populations, indicating that seedling recruitment is not uncommon in this species (Kleijn and Steinger 2002). It should be noted, however, that even a low rate of seedling establishment might be sufficient for maintenance of significant genetic variation (Watkinson and Powell 1993).

\section{ES Flowering Strategy: The Effect of Habitat and Reproductive Mode}

The ESS analysis demonstrated that we could accurately predict the flowering strategies in each of the three habitats. This analysis allowed for an age-structured seed bank and discrete seedling stage, size-dependent growth and survival, variation in growth between individuals within a population, size-dependent seed and ramet production, increase in ramet size with parent size, and differential sensitivity to density dependence in ramets and seedlings. The ESS analysis, however, also makes several simplifying assumptions and in the following we discuss these in light of our findings.

1. The population is at equilibrium $(\lambda=1)$. Lifehistory theory predicts that in rapidly expanding populations, selection favors shorter generation times (Charlesworth 1994). The age at first reproduction is thus expected to be an important determinant of an organism's potential population growth rate, because relatively small delays have disproportionate numerical penalties (Lewontin 1965). In agreement with these predictions, we found strong selection for early reproduction and small flowering sizes in all populations that were increasing rapidly; compare figure $4 A-4 C$ with figure $4 D-4 F$. Clearly, accurate prediction of the flowering strategy is possible only if we assume that the population growth is density dependent and the potential gains that accrue from early reproduction in increasing populations can have a dramatic effect on the optimal strategy. 
2. Pollen production is proportional to fecundity (eq. [10]). In many monocarpic plant species, individuals show size-dependent sex allocation, and plants generally become more female as they become larger (Klinkhamer et al. 1997). This changes the rate at which gains through sexual production accrue with size, the parameter $B$ in equation (11). If plants become more female as they become larger, then $B$, estimated from seed production data, will overestimate the true rate at which gains accrue with size, leading to an overestimate of the size at flowering (or an underestimate of the ESS $\beta_{0}$ ). Fortunately, the ESSs are not strongly affected by variation in $B$ (fig. $6 A-6 C$ ), and so we suspect the effect of size-dependent sex allocation will be relatively small in Veratrum.

3. The allocation of resources to sexual and asexual reproduction is fixed. Because resources are limited, we expect a trade-off between sexual and asexual reproduction (Stearns 1992). It is therefore likely that when preventing, say, sexual reproduction, more resources could be allocated to asexual reproduction (Piquot et al. 1998; Prati and Schmid 2000). Indeed, plants are known to switch between different reproductive modes in a phenotypic response to a changing environment, such as density (Douglas 1981) and resource availability (Gardner and Mangel 1999). These trade-offs may alter fecundity schedules in a sizedependent manner and thus the potential benefits accruing through reproductive delays. However, trade-offs between reproductive modes should not greatly affect our ESS predictions, because the reproductive mode has surprisingly little effect on the evolutionarily stable flowering strategy (fig. 6). Results from the analytical approximations indicated that this was mainly due to the insensitivity of the evolutionarily stable flowering strategy to changes in $B$, the slope of the size-fecundity relationship. Instead, the decision to flower strongly depended on the habitatspecific asymptotic size of individuals. Note that these approximations ignore the fact that large plants produce large vegetative offspring, suggesting that the decision to reproduce is primarily driven by the number of offspring produced rather than their quality. Thus, despite the complexity of Veratrum's life cycle, simple analytical approximations correctly predict the flowering strategy.

4. Density dependence is global, and so all seedlings (or clonal ramets) are affected equally. In reality, the effects of density dependence will be determined by the local density, which in turn depends on the pattern of dispersal of seeds and clonal ramets. In Veratrum, clonal ramets typically occur within $20 \mathrm{~cm}$ of their parent (Kleijn and Steinger 2002), whereas the winged seeds are dispersed by wind over at least several meters (E. Hesse, personal observation). This means that clonal ramets will experience a higher local density than one would predict from the global density, which reduces the expected fitness gains from the production of clonal ramets. This effect is captured in the parameter $c$ and results in $c$ being smaller then one might expect on the basis of the global density. The ESSs are largely unaffected by variation in $c$ (fig. 5), and so although the assumption of global density dependence is not realistic, it does not greatly affect the quantitative predictions.

5. The environment is constant. Several studies have demonstrated that temporal variation in demographic rates can have a substantial impact on the evolution of flowering decisions in monocarpic perennial herbs (Rees et al. 1999, 2004, 2006; Rose et al. 2002; Childs et al. 2004; Ellner and Rees 2007). The ability of a constant environment model to predict the ESS accurately does not imply that stochastic effects are small, because the effects can act in different directions (Rees et al. 2004, 2006). However, given the extremely high survival of established Veratrum plants, we suspect that the effects of temporal variation in the environment will be smaller than observed in other, shorter-lived species.

6. The size slope $\beta_{\mathrm{s}}$ of the flowering function is fixed at its estimated value to prevent the ESS from being a step function. There are several reasons why it might be impossible for plants to achieve a step function: (i) there is variable growth between when the decision to flower is made and when plant size is measured, (ii) plant size is not perfectly correlated with threshold flowering condition, and (iii) there may be genetic variation in the threshold condition (Childs et al. 2003). Indeed, several studies have demonstrated that natural populations harbor substantial genetic variation in the threshold sizes for flowering, which will be subject to selection (Wesselingh et al. 1997; de Jong and Klinkhamer 2005). Note that the ESS approach used here predicts only the best strategy, and currently we do not know whether this is achieved primarily through genetic variation, phenotypic plasticity, or some combination of both.

7. Several studies of long-lived monocarpic plants have found that within species, fast growth is associated with high survival (e.g., Young 1985; Burd et al. 2006), while between species, the opposite has been observed (Metcalf et al. 2006). If within a species some individuals are in consistently favorable habitats for growth and/or survival, then, as Burd et al. (2006) demonstrated, this may result in a reaction norm for flowering that encompasses a wide range of flowering sizes. This is consistent with the observation in natural systems that the size distribution of flowering and nonflowering individuals shows considerable overlap (Metcalf et al. 2003). The extent to which individuals are in consistently good or poor conditions can be assessed by fitting mixed models with individualspecific terms (Rees et al. 1999). In Veratrum, these terms were typically very small and so were dropped from the 
models, suggesting that adaptive reaction norms probably do not play a significant role in explaining the distribution of flowering sizes. Whether this is a general result for shortlived monocarpic plants is unclear, since Rose et al. (2002) report similar results for Carlina vulgaris, whereas Rees et al. (1999) found significant between-individual variation in the survival of Onopordum illyricum rosettes that was unrelated to size or age.

\section{Concluding Remarks}

Habitat is an important aspect of the selective environment and therefore is a significant factor in predicting the evolutionarily stable flowering strategy in natural Veratrum populations. The flowering strategy in turn is one of the key determinants of the dynamics of populations having a dramatic effect on both the rate of population change and the generation time, clearly indicating the importance of understanding the interplay between ecology and evolution (Hairston et al. 2005; Kokko and Lopez-Sepulcre 2007). These effects are also critical for understanding and predicting how populations will respond to environmental change, a topic of obvious applied importance.

\section{Acknowledgments}

We thank M. Macel for help during data collection and M. Dorken, T. Kawecki, J. Pannell, and M. Vos for commenting on an earlier draft of the manuscript. We also thank J. Antonovics, S. Ellner, S. Tuljapurkar, and L. Venable for advice on counting sexual versus asexual offspring. The project was funded by National Research Programme 48, Landscapes and Habitats of the Alps, of the Swiss National Science Foundation to H.M.-S.

\section{APPENDIX}

\section{Numerical Methods}

For numerical solution, it is convenient to express the integral projection model as a very large matrix containing all possible transitions, that is, nonzero entries whenever an individual contributes to next year's population. The life cycle of Veratrum comprises both discrete and continuous transitions, where dormant seeds of age $i\left(S_{i}\right)$ and cotyledons (C) are discrete points, $x_{1} \cdots x_{n}, y_{1} \cdots y_{n}$ are the mesh points for the size-structured established plant population, and $\Delta$ is the distance between successive meshpoints. In all calculations, we used 200 mesh points for established plant size.

$$
\begin{aligned}
& {\left[\begin{array}{c}
S_{1}(t+1) \\
S_{2}(t+1) \\
C(t+1) \\
n\left(y_{1}, t+1\right) \Delta \\
n\left(y_{2}, t+1\right) \Delta \\
\vdots \\
\vdots \\
n\left(y_{n}, t+1\right) \Delta
\end{array}\right]=} \\
& \left(\begin{array}{ccccccc}
0 & 0 & 0 & \left(1-g_{0}\right) s_{0} p_{\mathrm{f}}\left(x_{1}\right) f_{\mathrm{s}}\left(x_{1}\right) p_{\mathrm{s}}\left(x_{1}\right) & \cdots & \cdots & \left.\left(1-g_{0}\right) s_{0} p_{\mathrm{f}}\left(x_{n}\right) f_{\mathrm{s}}\left(x_{n}\right) p_{\mathrm{s}}\left(x_{n}\right)\right) \\
\left(1-g_{1}\right) s_{1} & 0 & 0 & 0 & & & 0 \\
g_{1} p_{\text {est }} & g_{2} p_{\text {est }} & 0 & g_{0} p_{\mathrm{f}}\left(x_{1}\right) f_{\mathrm{s}}\left(x_{1}\right) p_{\mathrm{s}}\left(x_{1}\right) p_{\text {est }} & \cdots & \cdots & g_{0} p_{\mathrm{f}}\left(x_{n}\right) f_{\mathrm{s}}\left(x_{n}\right) p_{\mathrm{s}}\left(x_{n}\right) p_{\text {est }} \\
0 & 0 & p_{\mathrm{sc}} f_{\mathrm{sd}}\left(y_{1}\right) \Delta & \left(p\left(y_{1}, x_{1}\right)+f\left(y_{1}, x_{1}\right)\right) \Delta & \cdots & \cdots & \left(p\left(y_{1}, x_{n}\right)+f\left(y_{1}, x_{n}\right)\right) \Delta \\
0 & 0 & p_{\mathrm{sc}} f_{\mathrm{sd}}\left(y_{2}\right) \Delta & \left(p\left(y_{2}, x_{1}\right)+f\left(y_{2}, x_{1}\right)\right) \Delta & \cdots & \cdots & \left(p\left(y_{2}, x_{n}\right)+f\left(y_{2}, x_{n}\right)\right) \Delta \\
\cdots & \cdots & \cdots & \cdots & \cdots & \cdots & \cdots \\
0 & 0 & p_{\mathrm{sc}} f_{\mathrm{sd}}\left(y_{n}\right) \Delta & \left(p\left(y_{n}, x_{1}\right)+f\left(y_{n}, x_{1}\right)\right) \Delta & \cdots & \cdots & \left(p\left(y_{n}, x_{n}\right)+f\left(y_{n}, x_{n}\right)\right) \Delta
\end{array}\right)\left[\begin{array}{c}
S_{1}(t) \\
S_{2}(t) \\
C(t) \\
n\left(x_{1}, t\right) \Delta \\
n\left(x_{2}, t\right) \Delta \\
\cdots \\
\cdots \\
n\left(x_{n}, t\right) \Delta
\end{array}\right] .
\end{aligned}
$$

\section{Literature Cited}

Benton, T. G., S. J. Plaistow, and T. N. Coulson. 2006. Complex population dynamics and complex causation: devils, details and demography. Proceedings of the Royal Society B: Biological Sciences 273:1173-1181.

Bronikowski, A. M., M. E. Clark, F. H. Rodd, and D. N. Reznick.
2002. Population-dynamic consequences of predator-induced life history variation in the guppy (Poecilia reticulata). Ecology 83: 2194-2204.

Burd, M., J. Read, G. D. Sanson, and T. Jaffré. 2006. Age-size plasticity for reproduction in monocarpic plants. Ecology 87:2755-2764.

Caswell, H. 1985. The evolutionary demography of clonal reproduction. Pages 187-224 in J. B. C Jackson, L. W. Buss, and R. E. 
Cook, eds. Population biology and evolution of clonal organisms. Yale University Press, New Haven, CT.

- 2001. Matrix population models: construction, analysis, and interpretation. Sinauer, Sunderland, MA.

Chambers, J. C. 1995. Relationships between seed fates and seedling establishment in an alpine ecosystem. Ecology 76:2124-2133.

Charlesworth, B. 1994. Evolution in age-structured populations. Cambridge University Press, Cambridge.

Cheptou, P.-O., and D. J. Schoen. 2007. Combining population genetic and demographic approaches in evolutionary studies of plant mating systems. Oikos 116:271-279.

Childs, D. Z., M. Rees, K. E. Rose, P. J. Grubb, and S. P. Ellner. 2003. Evolution of complex flowering strategies: an age- and size-structured integral projection model. Proceedings of the Royal Society B: Biological Sciences 270:1829-1838.

- 2004. Evolution of size-dependent flowering in a variable environment: construction and analysis of a stochastic integral projection model. Proceedings of the Royal Society B: Biological Sciences 271:425-434.

Cochran, M. E., and S. Ellner. 1992. Simple methods for calculating age-based life-history parameters for stage-structured populations. Ecological Monographs 62:345-364.

Cole, L. C. 1954. The population consequences of life history phenomena. Quarterly Review of Biology 29:103-137.

Cook, R. E. 1985. Growth and development in clonal plant populations. Pages 259-296 in J. B. C. Jackson, L. W. Buss, and R. E. Cook, eds. Population biology and evolution of clonal organisms. Yale University Press, New Haven, CT.

Coulson, T., T. G. Benton, P. Lundberg, S. R. X. Dall, B. E. Kendall, and J.-M. Gaillard. 2006. Estimating individual contributions to population growth: evolutionary fitness in ecological time. Proceedings of the Royal Society B: Biological Sciences 274:547-555.

de Jong, T. J., and P. G. L. Klinkhamer. 2005. Evolutionary ecology of plant reproductive strategies. Cambridge University Press, Cambridge.

Dorken, M. E., and S. C. H. Barrett. 2003. Life-history differentiation and the maintenance of monoecy and dioecy in Sagittaria latifolia (Alismataceae). Evolution 57:1973-1988.

Douglas, D. A. 1981. The balance between vegetative and sexual reproduction of Mimulus primuloides (Scrophulariaceae) at different altitudes in California. Journal of Ecology 69:295-310.

Easterling, M. R., S. P. Ellner, and P. M. Dixon. 2000. Size-specific sensitivity: applying a new structured population model. Ecology 81:694-708.

Ellner, S. P., and M. Rees. 2006. Integral projection models for species with complex demography. American Naturalist 167:410-428.

. 2007. Stochastic stable population growth in integral projection models: theory and application. Journal of Mathematical Biology 54:227-256.

Enquist, B. J., G. B. West, E. L. Charnov, and J. H. Brown. 1999. Allometric scaling of production and life-history variation in vascular plants. Nature 401:907-911.

Eriksson, O. 1993. Dynamics of genets in clonal plants. Trends in Ecology \& Evolution 8:313-316.

Eriksson, O., and J. Ehrlen. 1992. Seed and microsite limitation of recruitment in plant populations. Oecologia (Berlin) 91:360-364.

Forbis, T. A. 2003. Seedling demography in an alpine ecosystem. American Journal of Botany 90:1197-1206.

Forster, W., and T. A. Wohlfahrt. 1973. Die schmetterlinge Mitteleuropas. Spanner Franckh'sche Verlagshandlung, Stuttgart.
Fox, C. W., D. A. Roff, and D. J. Fairnbairn. 2001. Evolutionary ecology: concepts and case studies. Oxford University Press, Oxford.

Frederiksen, M., M. P. Harris, and S. Wanless. 2005. Inter-population variation in demographic parameters: a neglected subject? Oikos 111:209-214.

Gardner, S. N., and M. Mangel. 1999. Modeling investments in seeds, clonal offspring, and translocation in a clonal plant. Ecology 80: $1202-1220$.

Grace, J. B., and R. G. Wetzel. 1982. Niche differentiation between two rhizomatous plant species: Typha latifolia and Typha angustifolia. Canadian Journal of Botany 60:46-57.

Hairston, N. G., S. P. Ellner, M. A. Geber, T. Yoshida, and J. A. Fox. 2005. Rapid evolution and the convergence of ecological and evolutionary time. Ecology Letters 8:1114-1127.

Hautekeete, N. C., Y. Piquot, and H. van Dijk. 2002. Life span in Beta vulgaris ssp. maritima: the effects of age at first reproduction and disturbance. Journal of Ecology 90:508-516.

Heino, M., U. Dieckmann, and O. R. Godø. 2002. Measuring probabilistic reaction norms for age and size at maturation. Evolution 56:669-678.

Hesse, E., M. Rees, and H. Müller-Schärer. 2007. Seed bank persistence of clonal weeds in contrasting habitats: implications for control. Plant Ecology 190:233-243.

Kleijn, D., and H. Müller-Schärer. 2006. The relation between unpalatable species, nutrients and plant species richness in Swiss montane pastures. Biodiversity and Conservation 15:3971-3982.

Kleijn, D., and T. Steinger. 2002. Contrasting effects of grazing and hay cutting on the spatial and genetic population structure of Veratrum album, an unpalatable, long-lived, clonal plant species. Journal of Ecology 90:360-370.

Klinkhamer, P. G. L., T. J. de Jong, A. J. Metz, and J. Val. 1987. Life history tactics of annual organisms: the joint effect of dispersal and delayed germination. Theoretical Population Biology 32:127-156.

Klinkhamer, P. G. L., T. J. de Jong, and H. Metz. 1997. Sex and size in cosexual plants. Trends in Ecology \& Evolution 12:260-265.

Kokko, H., and A. Lopez-Sepulcre. 2007. The ecogenetic link between demography and evolution: can we bridge the gap between theory and data? Ecology Letters 10:773-782.

Lesica, P., and T. P. Young. 2005. A demographic model explains lifehistory variation in Arabis fecunda. Functional Ecology 19:471-477.

Lewontin, R. C. 1965. Selection for colonizing ability. Pages 79-94 in H. G. Baker and G. L. Stebbins, eds. The genetics of colonizing species. Academic Press, New York.

Maynard Smith, J. 1978. The evolution of sex. Cambridge University Press, Cambridge.

- 1982. Evolution and the theory of games. Cambridge University Press, Cambridge.

Metcalf, C. J. E., and S. Pavard. 2007. Why evolutionary biologists should be demographers? Trends in Ecology \& Evolution 22:205222.

Metcalf, C. J. E., M. Rees, J. M. Alexander, and K. Rose. 2006. Growthsurvival trade-offs and allometries in rosette-forming perennials. Functional Ecology 20:217-225.

Metcalf, J. C., K. E. Rose, and M. Rees. 2003. Evolutionary demography of monocarpic perennials. Trends in Ecology \& Evolution 18:471-480.

Munzbergova, Z., and T. Herben. 2005. Seed, dispersal, microsite, habitat and recruitment limitation: identification of terms and concepts in studies of limitations. Oecologia (Berlin) 145:1-8. Mylius, S. D., and O. Diekmann. 1995. On evolutionarily stable life 
histories, optimization and the need to be specific about density dependence. Oikos 74:218-224.

Oli, M. K., and F. S. Dobson. 2003. The relative importance of lifehistory variables to population growth rate in mammals: Cole's prediction revisited. American Naturalist 161:422-440.

Pan, J. J., and J. S. Price. 2002. Fitness and evolution in clonal plants: the impact of clonal growth. Evolutionary Ecology 15:583-600.

Partridge, L., and P. H. Harvey. 1988. The ecological context of life history evolution. Science 241:1449-1455.

Pfister, C. A., and F. R. Stevens. 2003. Individual variation and environmental stochasticity: implications for matrix model predictions. Ecology 84:496-510.

Pinheiro, J. C., and D. M. Bates. 2000. Mixed-effects models in S and S-PLUS: statistics and computing. Springer, New York.

Piquot, Y., D. Petit, M. Valero, J. Cuguen, P. de Laguerie, and P. Vernet. 1998. Variation in sexual and asexual reproduction among young and old populations of the perennial macrophyte Sparganium erectum. Oikos 82:139-148.

Prati, D., and B. Schmid. 2000. Genetic differentiation of life-history traits within populations of the clonal plant Ranunculus reptans. Oikos 90:442-456.

Rees, M., and K. E. Rose. 2002. Evolution of flowering strategies in Oenothera glazioviana: an integral projection model approach. Proceedings of the Royal Society B: Biological Sciences 269:1509-1515.

Rees, M., A. Sheppard, D. Briese, and M. Mangel. 1999. Evolution of size-dependent flowering in Onopordum illyricum: a quantitative assessment of the role of stochastic selection pressures. American Naturalist 154:628-651.

Rees, M., M. Mangel, L. A. Turnbull, A. Sheppard, and D. Briese. 2000. The effects of heterogeneity on dispersal and colonisation in plants. Pages 237-265 in M. Hutchings, J. E. A. John, and A. J. A. Stewart, eds. Ecological consequences of environmental heterogeneity. Blackwell, Oxford.

Rees, M., D. Z. Childs, K. E. Rose, and P. J. Grubb. 2004. Evolution of size-dependent flowering in a variable environment: partitioning the effects of fluctuating selection. Proceedings of the Royal Society B: Biological Sciences 271:471-475.

Rees, M., D. Z. Childs, J. C. Metcalf, K. E. Rose, A. W. Sheppard, and P. J. Grubb. 2006. Seed dormancy and delayed flowering in monocarpic plants: selective interactions in a stochastic environment. American Naturalist 168:E54-E71.

Reinartz, J. A. 1984. Life history variation of common mullein (Verbascum thapsus). I. Latitudinal differences in population dynamics and timing of reproduction. Journal of Ecology 72:897-912.

Reznick, D., M. J. Bryant, and F. Bashey. 2002. r- and K-selection revisited: the role of population regulation in life-history evolution. Ecology 83:1509-1520.

Reznick, D. A., H. Bryga, and J. A. Endler. 1990. Experimentally induced life-history evolution in a natural population. Nature 346: 357-359.

Reznick, D. N., M. J. Bryant, D. Roff, C. K. Ghalambor, and D. E. Ghalambor. 2004. Effect of extrinsic mortality on the evolution of senescence in guppies. Nature 431:1095-1099.

Rose, K. E., M. Rees, and P. J. Grubb. 2002. Evolution in the real world: stochastic variation and the determinants of fitness in Carlina vulgaris. Evolution 56:1416-1430.

Rose, K. E., S. M. Louda, and M. Rees. 2005. Demographic and evolutionary impacts of native and invasive insect herbivores on Cirsium canescens. Ecology 86:453-465.

Saether, B.-E., S. Engen, and E. Matthysen. 2002. Demographic characteristics and population dynamical patterns of solitary birds. Science 295:2070-2073.

Schaffner, U., D. Kleijn, V. Brown, and H. Müller-Schärer. 2001. Veratrum album L. in montane grasslands: a model system for implementing biological control in land management practices of high biodiversity habitats. Biocontrol News and Information 22: 19-28.

Schlapfer, M., H. Zoller, and C. Korner. 1998. Influences of mowing and grazing on plant species composition in calcareous grassland. Botanica Helvetica 108:57-67.

Shumway, S. W. 1995. Physiological integration among clonal ramets during invasion of disturbance patches in a New England salt marsh. Annals of Botany 76:225-233.

Sletvold, N. 2002. Effects of plant size on reproductive output and offspring performance in the facultative biennial Digitalis purpurea. Journal of Ecology 90:958-966.

Sletvold, N., and J. M. Grindeland. 2007. Fluctuating selection on reproductive timing in Digitalis purperea. Oikos 166:473-481.

Spiegelberger, T., H. Müller-Schärer, D. Matthies, and U. Schaffner. 2008. Sawdust addition reduces the productivity of nitrogenenriched mountain grasslands. Restoration Ecology (forthcoming).

Stearns, S. C. 1992. The evolution of life histories. Oxford University Press, Oxford.

Turnbull, L. A., M. J. Crawley, and M. Rees. 2000. Are plant populations seed-limited? a review of seed sowing experiments. Oikos $88: 225-238$.

Venables, W. N., and B. D. Ripley. 2002. Modern applied statistics with S-PLUS. Springer, New York.

Watkinson, A. R., and J. C. Powell. 1993. Seedling recruitment and the maintenance of clonal diversity in plant populations: a computer simulation of Ranunculus respens. Journal of Ecology 81: 707-717.

Weiner, J., S. Martinez, H. Müller-Schärer, P. Stoll, and B. Schmid. 1997. How important are environmental maternal effects in plants? a study with Centaurea maculosa. Journal of Ecology 85:133-142.

Weppler, T., P. Stoll, and L. Stocklin. 2006. The relative importance of sexual and clonal reproduction for population growth in the longlived alpine plant Geum reptans. Journal of Ecology 94:869-879.

Wesselingh, R. A., P. G. L. Klinkhamer, T. J. de Jong, and L. A. Boorman. 1997. Threshold size for flowering in different habitats: effects of size-dependent growth and survival. Ecology 78:2118-2132.

Young, T. P. 1985. Lobelia telekii herbivory, mortality, and size at reproduction: variation with growth rate. Ecology 66:1879-1883. - 1990. The evolution of semelparity in Mount Kenya lobelias. Evolutionary Ecology 4:157-171.

Associate Editor: Catherine A. Pfister Editor: Monica A. Geber 